\title{
Metabolic syndrome is a risk factor for cancer mortality in the general Japanese population: the Jichi Medical School Cohort Study
}

\author{
Jun Watanabe ${ }^{1}$, Eiichi Kakehi ${ }^{2}$, Kazuhiko Kotani ${ }^{1}$, Kazunori Kayaba ${ }^{3}$, Yosikazu Nakamura ${ }^{1}$ \\ and Shizukiyo Ishikawa ${ }^{1 *}$
}

\begin{abstract}
Background: Metabolic syndrome (MetS) and cancer are major public health problems worldwide. The relationship between MetS and cancer death is of great interest. We examined the predictive value of MetS for cancer mortality in Japan.

Methods: Study participants included 4495 men and 7028 women aged 18-90 years who were registered between 1992 and 1995 as part of the Jichi Medical School Cohort Study. We used a definition of MetS modified for the Japanese population. The primary outcome was cancer mortality. Additionally, the relationship between MetS and cancertype specific mortality was examined. Analyses were conducted with Cox's regression models adjusted for age, smoking status, alcohol drinking status, marital status, educational attainment, physical activity, occupational category, and menopausal status (only in women).

Results: During a mean follow-up of 18.5 years, 473 men and 297 women died from cancer. MetS was positively associated with cancer mortality in women (hazard ratio [HR], 1.69; 95\% confidence interval [CI] 1.21-2.36), but not in men $(\mathrm{HR}, 1.21 ; 95 \% \mathrm{Cl} 0.90-1.62)$. Additionally, MetS was associated with a high risk of colorectal $(\mathrm{HR}, 3.48 ; 95 \% \mathrm{Cl}$ 1.68-7.22) and breast ( $\mathrm{HR}, 11.90 ; 95 \% \mathrm{Cl} 2.25-62.84)$ cancer deaths in women.
\end{abstract}

Conclusion: MetS was a significant predictor of cancer mortality in women.

Keywords: Metabolic syndrome, Cohort studies, Neoplasm, Mortality, Japanese

\section{Background}

Metabolic syndrome (MetS) is a disease characterized by a cluster of high blood glucose, dyslipidemia, obesity, and hypertension [1]. MetS is an important risk factor for not only cardiovascular diseases (CVD) but also the development of cancer $[2,3]$. Accumulating evidence regarding the clinical value of MetS in estimating the risk of cancer

*Correspondence: i-shizu@jichi.ac.jp

${ }^{1}$ Division of Community and Family Medicine, Center for Community Medicine, Jichi Medical University, 3311-1 Yakushiji, Shimotsuke, Tochigi 329-0498, Japan

Full list of author information is available at the end of the article has led to increased interest in the relationship between MetS and cancer.

Cancer remains a major cause of death worldwide, with 14.1 million new cases and 8.2 million deaths from cancer occurring annually [4]. Of note, cancer deaths in Japan have been gradually increasing and now constitute the leading cause of death in the country [5]. Each component of MetS, viz., obesity [6], hypertension [7], hyperglycemia [8-11], and dyslipidemia [12], independently increases the risk of cancer. However, it remains unclear whether there is a dose-response association between MetS components and cancer mortality. Despite substantial interest in the relationship between MetS and cancer 
deaths, few studies have examined the contribution of the syndrome to cancer deaths [13-17].

We herein investigated the relationship between MetS and cancer mortality in a general Japanese population.

\section{Methods}

\section{Participants and follow-up}

The present study was a serial prospective populationbased cohort analysis using data from the Jichi Medical School (JMS) Cohort Study. The research design of the JMS Cohort Study and some descriptive data have been reported in detail elsewhere [18]. The study was initiated in 1992 to investigate the relationship between potential risk factors and CVD in the general Japanese population. Baseline data in 12 Japanese communities were obtained between April 1992 and July 1995 from national mass screening examinations for CVD, which were conducted according to the Health and Medical Service Law for the Aged in Japan. Local municipal governments sent personal invitations through the mail to all mass screening participants. Participants were aged 40-69 years in eight areas (Iwaizumi, Tako, Kuze, Sakuma, Sakugi, Okawa, Ainoshima, and Akaike), $\geq 35$ years in one area (Wara), and $\geq 18$ years in three areas (Hokudan, Yamato, and Takasu). We included 12,490 participants (4911 men and 7579 women), and the follow-up rate was $99 \%$ in 18 years from the data of baseline registration to the end of 2013. After the exclusion of 889 participants, including those who were lost to follow-up $(\mathrm{n}=97)$, had a history of cancer $(n=141)$, had missing data for height and weight $(\mathrm{n}=494)$ or blood pressure and blood samples $(\mathrm{n}=157)$, or died in the first 2 years of follow-up $(\mathrm{n}=78)$, the remaining 11,523 participants (4495 men and 7028 women) were eligible for the analysis.

The JMS Cohort Study conducted follow-up surveys until 31 December 2013. We obtained death certificates from public health centers with the permission of the Agency of General Affairs and the Ministry of Health, Labour and Welfare. Each municipal government collected annual data on participant relocation. In Japan, the registries of residency and deaths are established by law and doctors are trained to describe in standard format.

\section{Measurements and outcomes}

In the baseline survey, height without shoes and weight of clothed participants were measured, and body mass index (BMI) was calculated as weight $(\mathrm{kg}) /$ height $(\mathrm{m})^{2}$. Trained interviewers used a standardized questionnaire to obtain data, including smoking habit (never, past, or current smoker), alcohol drinking habit (never, past, or current drinker), medical history (past or present hypertension, diabetes, and hyperlipidemia, and the presence of these medication), marital status (yes or no), educational attainment (the age at completion of education), physical activity (the Framingham Study Questionnaire [19]), occupation, and menopause status (pre or post) in women. Educational attainment was categorized into less than junior high school ( $\leq 15$ years), high school (16-18 years), and more than high school ( $\geq 19$ years). Physical activity was categorized by using physical activity index (PAI) estimated by calculating the coefficients and time spent on an activity, into low (PAI $<30)$, middle (PAI $=30-39)$, and high $(\mathrm{PAI} \geq 40)$ in this study [19-21]. Occupation was categorized into white-collar, blue-collar, or no working. Sales workers, clerks, professional/technicians, and service workers were categorized as white-collar occupations. Agriculture and forestry, fishery, security, transportation/communications, civil engineering and construction, and craft workers/laborers were categorized as blue-collar occupations, while retiree and inoccupation were categorized as no working [22]. Systolic blood pressure (SBP) and diastolic blood pressure (DBP) were measured using a fully automated sphygmomanometer, BP203RV-II (Nippon Colin Co., Ltd., Komaki, Japan), on the right arm in the sitting position after at least $5 \mathrm{~min}$ of rest. Serum total cholesterol (TC), high-density lipoprotein cholesterol (HDL-C), triglyceride (TG), and plasma glucose (PG) concentrations were measured using enzymatic methods, as previously reported [18].

Information on the causes of death were determined by death certificates and coded using the International Classification of Diseases 10th revision (ICD-10). The primary endpoint was total cancer deaths (C00-C97), and secondary outcomes were lung (C33-34), stomach (C16), colon (C18), rectum (C19-20), liver (C22), gallbladder (C23), prostate (C61), and breast (C50) cancer deaths.

\section{Definition}

We applied the modified Japanese MetS definition using BMI instead of waist circumference (WC) because only approximately $20 \%$ of all participants in the JMS Cohort Study had WC measured, and BMI $\geq 25 \mathrm{~kg} / \mathrm{m}^{2}$ is consistent with a WC of $\geq 85 \mathrm{~cm}$ in men and $\geq 90 \mathrm{~cm}$ in women in Japan [23]. MetS was defined as BMI $\geq 25 \mathrm{~kg} /$ $\mathrm{m}^{2}$ and the presence of two or more of the following: (i) SBP and/or DBP $\geq 130 / 85 \mathrm{mmHg}$ or the use of antihypertensive medication; (ii) $\mathrm{TG} \geq 1.69 \mathrm{mmol} / \mathrm{L}(150 \mathrm{mg} /$ $\mathrm{dL})$ and/or HDL-C $<1.03 \mathrm{mmol} / \mathrm{L}(40 \mathrm{mg} / \mathrm{dL})$ and/or the use of antihyperlipidemic medication; and (iii) fasting $\mathrm{PG} \geq 6.1 \mathrm{mmol} / \mathrm{L}(110 \mathrm{mg} / \mathrm{dL})$ (with a fasting duration of at least $3 \mathrm{~h}$ ) or casual PG (for less than $3 \mathrm{~h}$ or without regard to the time since the last meal) $\geq 7.8 \mathrm{mmol} / \mathrm{L}$ $(140 \mathrm{mg} / \mathrm{dL})$ and/or the use of antidiabetic medication. 


\section{Statistical analysis}

Summary statistics were used to compare the characteristics of participants with and without MetS using the Mann-Whitney $U$ test and $x^{2}$ test. To elucidate the relationship between MetS and cancer mortality, a Cox's proportional hazards regression model was constructed to estimate multivariate-adjusted hazard ratios (HRs) and 95\% confidence intervals (CIs) for cancer mortality to the number of metabolic risk factors, the obesity category $\left(\mathrm{BMI} \geq 25 \mathrm{~kg} / \mathrm{m}^{2}\right.$ or $\left.<25 \mathrm{~kg} / \mathrm{m}^{2}\right)$, and MetS by sex, adjusting for age, smoking status (never, past, or current smoker), alcohol drinking status (never, past, or current drinker), marital status (yes or no), educational attainment $(\leq 15,16-18$, or $\geq 19$ years), physical activity (low, middle, high), occupation category (white-collar, blue-collar, or no working), and menopausal status (pre or post) only in women at baseline. These covariates are commonly adjusted for in cancer risk. However, tests for linear trend across the number of metabolic risk factors were conducted by including an ordinal scoring in the models to examine a dose-response association between MetS component and cancer mortality. The proportional hazards assumption for the model was checked by examining the log-negative-log plot of the survival function for participants with and without MetS, and the number of MetS components against time to death/follow-up time. These curves help in identifying non-proportionality patterns in hazard function such as crossing of the curves, convergent, or divergent. Additionally, we conducted Cox's regression analysis by age $\geq 65$ years or $<65$ years and estimated multivariate adjusted HRs for cancer mortality to each metabolic risk factor, and for cancer-type specific mortality associated with MetS by sex. We performed sensitivity analyses by excluding participants who were younger than 40 years at baseline to minimize the influence of a younger generation. The threshold for significance was $\mathrm{P}<0.05$. All statistical analyses were conducted using IBM SPSS version 25.0 (IBM Corp., Armonk, NY, USA).

\section{Results}

The baseline characteristics of subjects with and without MetS are summarized for both the sexes in Table 1. The mean follow-up period was 18.5 (standard deviation [SD], 4.6) years. The median age of participants was 58 (interquartile range [IQR], 46-64) years in men and 57 (IQR, 47-64) years in women, and $91.3 \%$ of participants were older than 40 years. At baseline, $11.6 \%$ of men and $8.9 \%$ of women had MetS. There were no significant differences in smoking in men and women and alcohol drinking in men between participants with and without MetS. Both men and women with MetS had higher BMI,
SBP, DBP, PG, TC and TG levels and lower HDL-C levels, compared to without MetS.

Figure 1 shows adjusted hazard curves of cancer mortality with the number of MetS components by Cox regression analysis. The proportional hazards assumption for the model was reasonable because the log-negativelog plot showed the separate lines did not cross and were not convergent, and divergent in Additional file 1: Figure S1. Table 2 shows HRs and 95\% CIs for cancer mortality with the number of Japanese MetS components and obesity category. Increases in the number of Japanese MetS components showed a linear association with the HRs for cancer mortality ( $P$ for trend $=0.007$ ), especially in women ( $P$ for trend $=0.027$ ), but not in men ( $P$ for trend $=0.10$ ). The effects of obesity with $2-3$ metabolic risk factors were significantly greater than those in participants who were not obese and had no risk factors, whereas the effects of not being obese but having 2-3 risk factors were not, especially in women.

Figure 2 shows adjusted hazard curves of cancer mortality with metabolic syndrome by Cox regression analysis. The proportional hazard assumption for the model was reasonable in Additional file 1: Figure S2. Table 3 shows the number of deaths, crude mortality rates, and adjusted HRs for cancer mortality by sex. During the follow-up period, 770 deaths due to cancer (473 men and 297 women) occurred. Age-adjusted HRs were 1.11 (95\% CI 0.84-1.48) in men and 1.69 (95\% CI 1.23-2.31) in women. Multivariate-adjusted HRs were 1.21 (95\% CI $0.90-1.62)$ in men and 1.69 (95\% CI 1.21-2.36) in women. In addition, among women younger than 65 years, MetS was associated with a significantly increased risk of cancer mortality (multivariate-adjusted HR 1.66; 95\% CI 1.09-2.55), whereas among women older than 65 years, there was no relationship between MetS and cancer mortality (multivariate-adjusted HR 1.69; 95\% CI 0.99-2.89).

Table 4 shows the predictive effect of each MetS component on cancer mortality. The effects of obesity in women (multivariate-adjusted HR 1.48; 95\% CI 1.151.91 ) and elevated PG in both men (multivariate-adjusted HR 1.49; 95\% CI 1.18-1.88) and women (multivariateadjusted HR 1.44; 95\% CI 1.03-2.03) on predicting cancer mortality were significantly greater in participants with MetS than in those without the syndrome.

Table 5 shows HRs and 95\% CIs for cancer-type specific mortality with MetS by sex. The multivariate-adjusted HRs of death from colorectal and breast cancers were 3.48 (95\% CI 1.68-7.22) and 11.90 (95\% CI 2.25-62.84), respectively, in women. However, no significant difference was observed between MetS and any cancer-type specific mortality in men.

Sensitivity analyses performed by excluding participants who were younger than 40 years at baseline were 
Table 1 Baseline characteristics of participants with or without metabolic syndrome by sex

\begin{tabular}{|c|c|c|c|c|c|c|c|c|c|c|}
\hline & \multicolumn{4}{|l|}{ Men } & \multirow[t]{3}{*}{$\mathrm{P}^{\mathrm{a}}$} & \multicolumn{4}{|c|}{ Women } & \multirow[t]{3}{*}{$P^{a}$} \\
\hline & \multicolumn{2}{|c|}{ Without MetS } & \multicolumn{2}{|c|}{ With MetS } & & \multicolumn{2}{|c|}{ Without MetS } & \multicolumn{2}{|c|}{ With MetS } & \\
\hline & $\mathbf{N}$ & $\%$ & $\mathbf{N}$ & $\%$ & & $\mathbf{N}$ & $\%$ & $\mathbf{N}$ & $\%$ & \\
\hline \multirow[t]{2}{*}{ Number of participants } & 3973 & 88.4 & 522 & 11.6 & & 6406 & 91.1 & 622 & 8.9 & \\
\hline & $\mathbf{N}$ & Median (IQR) & $\mathbf{N}$ & Median (IQR) & $\mathrm{P}^{\mathrm{a}}$ & $N$ & Median (IQR) & $\mathbf{N}$ & Median (IQR) & $P^{a}$ \\
\hline Age (year) & & $58(45-64)$ & & $56(46-63)$ & 0.016 & & $57(47-64)$ & & $60(53-65)$ & $<0.001$ \\
\hline BMI $\left(\mathrm{kg} / \mathrm{m}^{2}\right)$ & & $22.4(20.8-24.0)$ & & $26.6(25.8-28.1)$ & $<0.001$ & & $22.6(20.8-24.4)$ & & $27.0(25.9-28.9)$ & $<0.001$ \\
\hline $\mathrm{SBP}(\mathrm{mmHg})$ & & $128(115-141)$ & & $144(135-156)$ & $<0.001$ & & $124(112-139)$ & & $143(134-156)$ & $<0.001$ \\
\hline $\mathrm{DBP}(\mathrm{mmHg})$ & & $77(70-86)$ & & $88(82-94)$ & $<0.001$ & & $75(67-83)$ & & $86(80-92)$ & $<0.001$ \\
\hline Plasma Glucose (mmol/L) & & $5.4(4.9-6.1)$ & & $6.0(5.3-7.1)$ & $<0.001$ & & $5.3(4.9-5.8)$ & & $6.0(5.2-7.1)$ & $<0.001$ \\
\hline Total cholesterol (mmol/L) & & $4.7(4.2-5.3)$ & & $5.1(4.4-5.7)$ & $<0.001$ & & $5.0(4.4-5.6)$ & & $5.4(4.8-6.0)$ & $<0.001$ \\
\hline HDL-cholesterol (mmol/L) & & $1.2(1.1-1.5)$ & & $1.0(0.9-1.2)$ & $<0.001$ & & $1.3(1.2-1.6)$ & & $1.1(1.0-1.3)$ & $<0.001$ \\
\hline Triglyceride $(\mathrm{mmol} / \mathrm{L})$ & & $1.1(0.8-1.6)$ & & $2.1(1.5-2.8)$ & $<0.001$ & & $1.0(0.7-1.4)$ & & $1.9(1.4-2.5)$ & $<0.001$ \\
\hline Smoking & & $\%$ & & $\%$ & & & $\%$ & & $\%$ & \\
\hline Current & 1946 & 49.0 & 230 & 44.1 & 0.101 & 336 & 5.3 & 30 & 4.8 & 0.345 \\
\hline Former & 1062 & 26.7 & 149 & 28.5 & & 174 & 2.7 & 11 & 1.8 & \\
\hline Never & 804 & 20.2 & 120 & 23.0 & & 5535 & 86.4 & 541 & 87.1 & \\
\hline Data missing & 161 & 4.1 & 23 & 4.4 & & 361 & 5.6 & 40 & 6.3 & \\
\hline \multicolumn{11}{|l|}{ Alcohol drinking } \\
\hline Current & 2811 & 70.8 & 343 & 65.7 & 0.210 & 1488 & 23.2 & 120 & 19.3 & 0.022 \\
\hline Former & 123 & 3.1 & 22 & 4.2 & & 78 & 1.2 & 14 & 2.2 & \\
\hline Never & 788 & 19.8 & 107 & 20.5 & & 4353 & 68.0 & 411 & 66.1 & \\
\hline Data missing & 251 & 6.3 & 50 & 9.6 & & 487 & 7.6 & 77 & 12.4 & \\
\hline Diabetes mellitus & 83 & 2.1 & 22 & 4.2 & 0.002 & 67 & 1.0 & 43 & 6.9 & $<0.001$ \\
\hline Hypertension & 334 & 8.4 & 99 & 19.0 & $<0.001$ & 619 & 9.7 & 205 & 33.0 & $<0.001$ \\
\hline Hyperlipidemia & 43 & 1.1 & 11 & 2.1 & 0.002 & 93 & 1.5 & 49 & 7.9 & $<0.001$ \\
\hline \multicolumn{11}{|l|}{ Marital status } \\
\hline Married & 3644 & 91.7 & 473 & 90.6 & 0.278 & 5867 & 91.6 & 570 & 91.6 & 0.957 \\
\hline Single & 310 & 7.8 & 48 & 9.2 & & 519 & 8.1 & 50 & 8.0 & \\
\hline Data missing & 19 & 0.5 & 1 & 0.2 & & 20 & 0.3 & 2 & 0.3 & \\
\hline \multicolumn{11}{|l|}{ Education } \\
\hline$\leq 15$ years & 1766 & 44.5 & 224 & 42.9 & 0.730 & 3176 & 49.6 & 364 & 58.5 & $<0.001$ \\
\hline $16-18$ years & 1683 & 42.4 & 231 & 44.3 & & 2558 & 39.9 & 213 & 34.2 & \\
\hline$\geq 19$ years & 503 & 12.7 & 67 & 12.8 & & 650 & 10.1 & 43 & 6.9 & \\
\hline Data missing & 21 & 0.5 & 0 & 0 & & 22 & 0.3 & 2 & 0.3 & \\
\hline \multicolumn{11}{|l|}{ Physical activity } \\
\hline Low & 1232 & 31.0 & 204 & 39.1 & 0.001 & 2813 & 43.9 & 276 & 44.4 & 0.321 \\
\hline Middle & 1824 & 45.9 & 211 & 40.4 & & 2942 & 45.9 & 293 & 47.1 & \\
\hline High & 730 & 18.4 & 81 & 15.5 & & 335 & 5.2 & 24 & 3.9 & \\
\hline Data missing & 187 & 4.7 & 26 & 5.0 & & 316 & 4.9 & 29 & 4.7 & \\
\hline \multicolumn{11}{|l|}{ Occupation } \\
\hline White-collar & 869 & 21.9 & 142 & 27.2 & 0.002 & 1491 & 23.3 & 125 & 20.1 & $<0.001$ \\
\hline Blue-collar & 2548 & 64.1 & 296 & 56.7 & & 2296 & 35.8 & 192 & 30.9 & \\
\hline No working & 532 & 13.4 & 84 & 16.1 & & 2596 & 40.5 & 303 & 48.7 & \\
\hline Data missing & 24 & 0.6 & 0 & 0 & & 23 & 0.4 & 2 & 0.3 & \\
\hline
\end{tabular}

MetS metabolic syndrome, BMI body mass index, SBP systolic blood pressure, DBP diastolic blood pressure, HDL high-density lipoprotein, IQR interquartile range

a The Mann-Whitney $\mathrm{U}$ test or $\mathrm{X}^{2}$ test were performed 


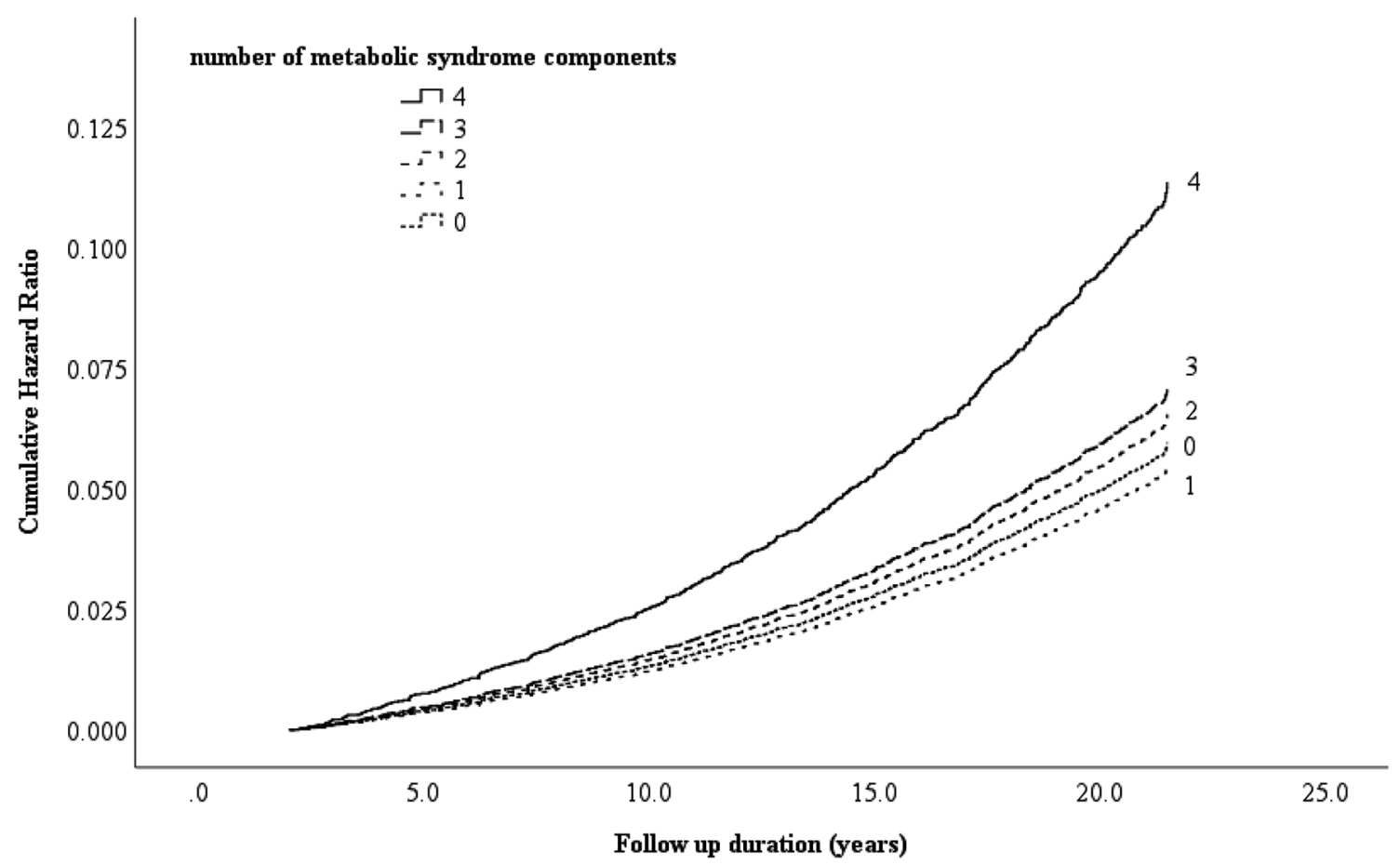

Fig. 1 Adjusted hazard curves of cancer mortality with the number of metabolic syndrome components

consistent with the primary findings. These analyses are described in Additional file 1: Table S1.

\section{Discussion}

In the present study, we demonstrated that MetS was associated with increased cancer deaths in women, particularly those younger than 65 years, over a mean follow-up duration of 18.5 years. The predictive value for cancer mortality increased with a higher number of MetS components. The results of the present study are important because the predictive value of MetS for cancer mortality in Japan has not been previously proven.

Only four recent cohort studies have reported a relationship between MetS and cancer mortality [14-17]. Prospective cohort studies in the U.S. reported that the National Cholesterol Education Program Adult Treatment Panel III (NCEP-ATP III) MetS using WC was associated with an increased risk of cancer mortality in men [14], or was not divided by sex [15]. Another prospective cohort study in Korea reported that the NECP-ATP III MetS using BMI instead of WC was associated with increased cancer-related mortality in men, but not in women [16]. The participants in the three cited NCEPATP III studies were younger than those in the present study. The number of cancer deaths was small and the prevalence of MetS was also low in the younger generation. In addition, while high estrogen levels may protect against the adverse effects of MetS in young women, MetS and central obesity may affect the risk of cancer in postmenopausal women [24-26]. However, the results of sensitivity analyses that excluded participants who were younger than 40 years of age at baseline were similar to the primary findings. The Japan Public Health Centerbased prospective study (JPHC), which included 34,051 participants (12,412 men and 21,639 women) over a follow-up of 12.3 years, reported that the Japanese MetS using BMI instead of WC was not associated with significantly increased cancer mortality in either sexes [17]. 


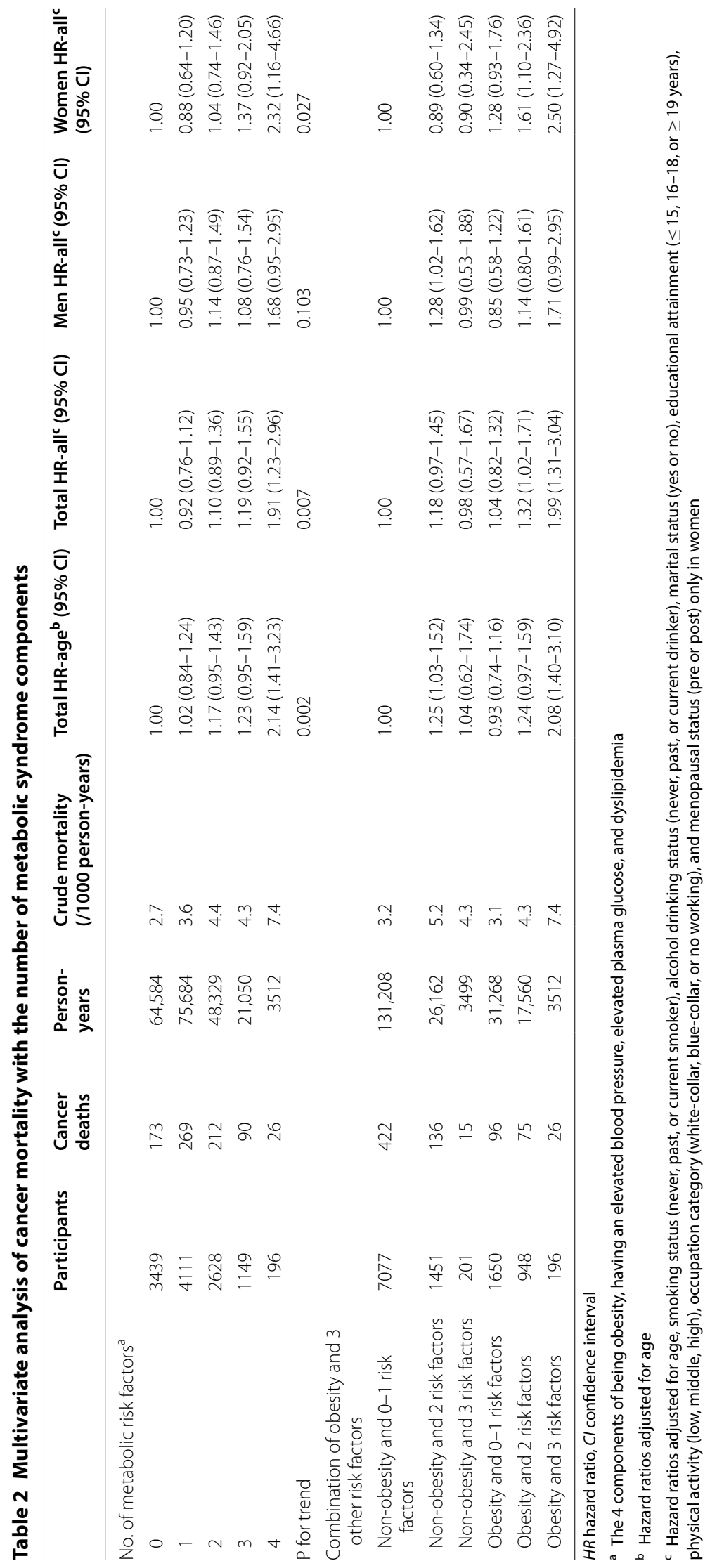



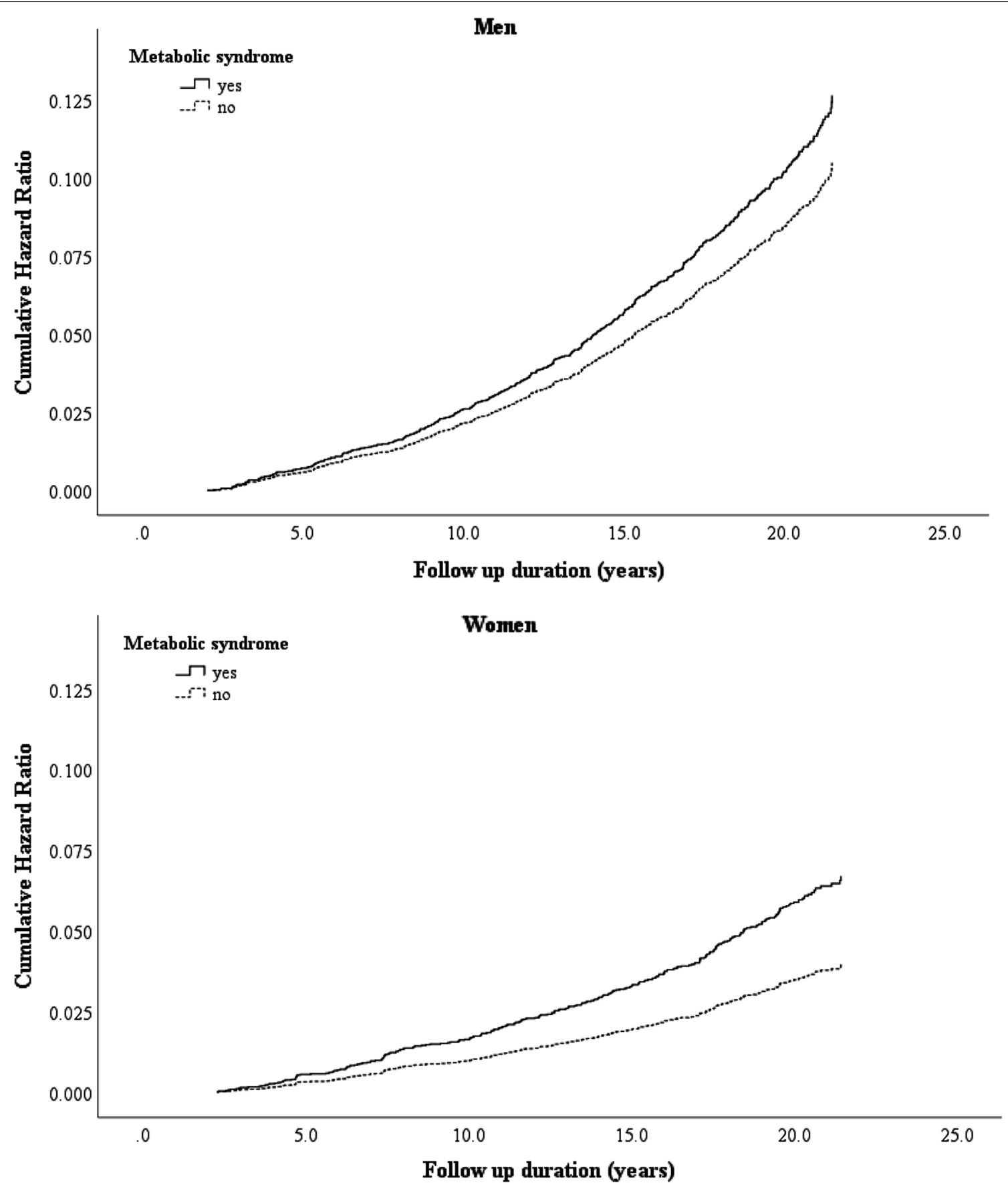

Fig. 2 Adjusted hazard curves of cancer mortality with metabolic syndrome by sex

The reason for these JPHC study results may be that this study calculated BMI using a self-administered questionnaire. The current study corroborates these findings and extends them by demonstrating that MetS predicts cancer mortality in women.
The present study also showed that the linear association between increases in the number of MetS components and cancer deaths, and the pathology of obesity is key in MetS because the presence of obesity affected the relationship between the number of MetS components 
Table 3 Multivariate analysis of cancer mortality with metabolic syndrome by sex

\begin{tabular}{|c|c|c|c|c|}
\hline & \multicolumn{2}{|l|}{ Men } & \multicolumn{2}{|l|}{ Women } \\
\hline & Without MetS & With MetS & Without MetS & With MetS \\
\hline MetS participants, n (\%) & $3973(88.4)$ & $522(11.6)$ & $6406(91.1)$ & $622(8.9)$ \\
\hline Cancer deaths & 418 & 55 & 251 & 46 \\
\hline Parson-Years & 71,444 & 9418 & 120,718 & 11,654 \\
\hline \multicolumn{5}{|l|}{ Cancer mortality } \\
\hline Crude mortality (/1000 person-years) & 5.9 & 5.8 & 2.1 & 3.9 \\
\hline $\operatorname{HR}-A g e^{a}(95 \%$ Cl) & 1.0 (reference) & $1.11(0.84-1.48)$ & 1.0 (reference) & $1.69(1.23-2.31)$ \\
\hline HR-All ${ }^{\mathrm{b}}(95 \% \mathrm{Cl})$ & 1.0 (reference) & $1.21(0.90-1.62)$ & 1.0 (reference) & $1.69(1.21-2.36)$ \\
\hline \multicolumn{5}{|l|}{$<65$ years old } \\
\hline Crude mortality (/1000 person-years) & 3.3 & 3.8 & 1.3 & 2.4 \\
\hline HR-Age $^{\mathrm{a}}(95 \% \mathrm{Cl})$ & 1.0 (reference) & $1.14(0.80-1.61)$ & 1.0 (reference) & $1.70(1.14-2.55)$ \\
\hline HR-All $(95 \%$ Cl) & 1.0 (reference) & $1.22(0.84-1.77)$ & 1.0 (reference) & $1.66(1.09-2.55)$ \\
\hline \multicolumn{5}{|l|}{$\geq 65$ years old } \\
\hline Crude mortality (/1000 person-years) & 2.6 & 2.0 & 0.8 & 1.5 \\
\hline $\operatorname{HR}-A g e^{a}(95 \%$ Cl) & 1.0 (reference) & $1.09(0.68-1.74)$ & 1.0 (reference) & $1.71(1.03-2.83)$ \\
\hline HR-All ${ }^{b}(95 \%$ Cl) & 1.0 (reference) & $1.19(0.73-1.95)$ & 1.0 (reference) & $1.69(0.99-2.89)$ \\
\hline
\end{tabular}

MetS metabolic syndrome, $\mathrm{HR}$ hazard ratio, $\mathrm{Cl}$ confidence interval

a Hazard ratios adjusted for age

b Hazard ratios adjusted for age, smoking status (never, past, or current smoker), alcohol drinking status (never, past, or current drinker), marital status (yes or no), educational attainment ( $\leq 15,16-18$, or $\geq 19$ years), physical activity (low, middle, high), occupation category (white-collar, blue-collar, or no working), and menopausal status (pre or post) only in women

and cancer mortality, whereas the absence of obesity did not. Previous studies also reported a dose-response relationship between MetS components and cancer mortality [14-16] as well as the risk of cancer [27].

MetS was positively associated with the risk of colorectal and breast cancer deaths in women. However, the number of cancer-type specific deaths was small. Previous cohort studies reported that MetS was positively associated with cancer mortality in the gastrointestinal system [28], particularly that of colorectal cancer [13, 29]. The Japan Collaborative Cohort Study (JACC) of 96,081 participants (40,510 men and 55,571 women), a nationwide prospective cohort study, reported increased colorectal cancer mortality in women, but not men, with diabetes [30]. A previous meta-analysis reported that MetS was associated with the risk of postmenopausal breast cancer [31].

While many definitions of MetS have been used worldwide, such as the NCEP [32, 33] and International Diabetes Federation (IDF) [34], the original MetS diagnostic criteria were defined in Japan [35]. NCEP and IDF representatives recently agreed that obesity is not an essential item for diagnosis because the clustering of metabolic risk factors is more important than obesity [36]. Therefore, only the Japanese criteria for MetS maintains that obesity is an essential component because it plays a major role in MetS [35]. Although the concept requiring obesity as an indispensable item was based on the pathogenesis of MetS, future studies need to focus on identifying the relationship between cancer and MetS using various criteria (see Additional file 1: Table S2).

There was no significant difference in smoking between participants with and without MetS in both sexes. However, men with MetS smoked more $\geq 21$ cigarettes per day than men without MetS (not shown in Table, $18.2 \%$ vs. $13.1 \%, \mathrm{P}<0.001)$. Current smoker in women may have less impact on MetS than in men because women had lower current smoker than men. There was no significant difference in alcohol drinking between participants with and without MetS in men, while women with MetS were significantly lower alcohol drinkers than women without MetS. One of the reasons may be that light to moderate alcohol consumption decreased the incidence of diabetes [37]. The trends in smoking and alcohol drinking of participants with and without MetS were similar in recent Japanese studies $[17,38,39]$.

The mechanisms responsible for the relationship between MetS and an increased risk of cancer death remain unclear; however, potential factors include obesity, insulin resistance, and the insulin-like growth factor (IGF) system [40]. Obesity is associated with inflammation, which leads to insulin resistance [41]. Insulin 
Table 4 Multivariate analysis of cancer mortality with metabolic syndrome according to each metabolic risk factor by sex

\begin{tabular}{|c|c|c|c|c|c|c|c|}
\hline & Presence & Participants & Cancer deaths & Parson-years & $\begin{array}{l}\text { Crude mortality } \\
\text { (/1000 person- } \\
\text { years) }\end{array}$ & $\mathrm{HR}^{-a g e}{ }^{\mathrm{a}}(95 \% \mathrm{Cl})$ & HR-all ${ }^{b}(95 \% \mathrm{Cl})$ \\
\hline \multicolumn{8}{|l|}{ Men } \\
\hline \multirow[t]{2}{*}{ Obesity } & No & 3484 & 378 & 62,224 & 6.1 & 1.00 & 1.00 \\
\hline & Yes & 1011 & 95 & 18,602 & 5.1 & $0.97(0.77-1.21)$ & $0.99(0.78-1.26)$ \\
\hline \multirow[t]{2}{*}{ Elevated blood pressure } & No & 2053 & 191 & 37,693 & 5.1 & 1.00 & 1.00 \\
\hline & Yes & 2442 & 282 & 43,150 & 6.5 & $0.96(0.80-1.16)$ & $0.99(0.82-1.21)$ \\
\hline \multirow[t]{2}{*}{ Elevated plasma glucose } & No & 3833 & 378 & 69,607 & 5.4 & 1.00 & 1.00 \\
\hline & Yes & 662 & 95 & 11,247 & 8.4 & $1.46(1.17-1.83)$ & $1.49(1.18-1.88)$ \\
\hline \multirow[t]{2}{*}{ Dyslipidemia } & No & 2676 & 280 & 48,221 & 5.8 & 1.00 & 1.00 \\
\hline & Yes & 1819 & 193 & 32,633 & 5.9 & $1.15(0.96-1.38)$ & $1.10(0.91-1.34)$ \\
\hline \multicolumn{8}{|l|}{ Women } \\
\hline \multirow[t]{2}{*}{ Obesity } & No & 5245 & 195 & 98,606 & 2.0 & 1.00 & 1.00 \\
\hline & Yes & 1783 & 102 & 33,717 & 3.0 & $1.44(1.14-1.83)$ & $1.48(1.15-1.91)$ \\
\hline \multirow[t]{2}{*}{ Elevated blood pressure } & No & 3657 & 127 & 69,337 & 1.8 & 1.00 & 1.00 \\
\hline & Yes & 3371 & 170 & 63,004 & 2.7 & $1.04(0.82-1.31)$ & $1.02(0.80-1.31)$ \\
\hline \multirow[t]{2}{*}{ Elevated plasma glucose } & No & 6403 & 256 & 120,761 & 2.1 & 1.00 & 1.00 \\
\hline & Yes & 625 & 41 & 11,556 & 3.5 & $1.37(0.98-1.91)$ & $1.44(1.03-2.03)$ \\
\hline \multirow[t]{2}{*}{ Dyslipidemia } & No & 5143 & 208 & 96,688 & 2.2 & 1.00 & 1.00 \\
\hline & Yes & 1885 & 89 & 35,664 & 2.5 & $1.03(0.80-1.31)$ & $1.04(0.80-1.34)$ \\
\hline
\end{tabular}

Obesity: body mass index $\geq 25 \mathrm{~kg} / \mathrm{m}^{2}$

Elevated blood pressure: systolic blood pressure and/or diastolic blood pressure $\geq 130 / 85 \mathrm{mmHg}$ or the use of antihypertensive medication

Elevated plasma glucose: fasting plasma glucose $\geq 6.1 \mathrm{mmol} / \mathrm{L}(110 \mathrm{mg} / \mathrm{dL}$ ) (with a fasting duration of at least $3 \mathrm{~h}$ ) or casual plasma glucose (for less than $3 \mathrm{~h}$ or without regard to the time since the last meal $) \geq 7.8 \mathrm{mmol} / \mathrm{L}(140 \mathrm{mg} / \mathrm{dL})$ and $/$ or the use of antidiabetic medication

Dyslipidemia: triglycerides $\geq 1.69 \mathrm{mmol} / \mathrm{L}(150 \mathrm{mg} / \mathrm{dL}$ ) and/or high-density lipoprotein cholesterol $<1.03 \mathrm{mmol} / \mathrm{L}$ (40 mg/dL) and/or the use of antihyperlipidemic medication

$H R$ hazard ratio, $\mathrm{Cl}$ confidence interval

a Hazard ratios adjusted for age

b Hazard ratios adjusted for age, smoking status (never, past, or current smoker), alcohol drinking status (never, past, or current drinker), marital status (yes or no), educational attainment ( $\leq 15,16-18$, or $\geq 19$ years), physical activity (low, middle, high), occupation category (white-collar, blue-collar, or no working), and menopausal status (pre or post) only in women

resistance is a key factor in MetS and increases the risk of cancer mortality $[42,43]$. Insulin stimulates the synthesis of IGF-1 and leads to tumor growth [44]. The present study demonstrated that MetS increased cancer deaths in women, but not in men. BMI is a useful indicator of overall adiposity, including visceral adipose tissue (VAT), and VAT is more strongly associated with metabolic risk factors in women than in men $[45,46]$. VAT has a direct negative effect on health by releasing a larger amount of excess free fatty acids (FFAs) in women than in men [47]. Triglyceride/FFA cycling is central to the obesity-mediated risk of cancer [48]. Further research is needed to confirm the mechanisms underlying sex-related factors.

The present study has several potential limitations. The measurement of MetS was based on a single measurement only at baseline, which made it impossible to evaluate the effect of changes in metabolic risk factors over time on cancer mortality. Furthermore, we defined obesity of MetS using BMI instead of WC. Although WC and BMI can produce slight differences in the diagnostic performance and pathological meaning of MetS, BMI $\geq 25 \mathrm{~kg} / \mathrm{m}^{2}$ correlates highly well with a WC of $\geq 85 \mathrm{~cm}$ in men and $\geq 90 \mathrm{~cm}$ in Japan [23]. In addition, owing to the small number of cancer-type specific deaths, there was a possibility of not only beta errors, but also chance.

\section{Conclusion}

The present results suggest that MetS is a significant predictor of cancer death in women. Furthermore, there is a dose-response association between an increasing 
Table 5 Multivariate analysis of cancer-type specific mortality with metabolic syndrome by sex

\begin{tabular}{|c|c|c|c|c|c|c|}
\hline & $\begin{array}{l}\text { Presence } \\
\text { of MetS }\end{array}$ & Cancer deaths & Parson-years & $\begin{array}{l}\text { Crude mortality } \\
\text { (/1000 person-years) }\end{array}$ & HR-age $^{a}(95 \% \mathrm{Cl})$ & HR-all $^{\mathbf{b}}(95 \% \mathrm{Cl})$ \\
\hline \multicolumn{7}{|l|}{ Men } \\
\hline \multirow[t]{2}{*}{ Lung } & No & 132 & 2374 & 1.8 & 1.00 & 1.00 \\
\hline & Yes & 14 & 256 & 1.5 & $0.91(0.52-1.58)$ & $1.13(0.65-1.98)$ \\
\hline \multirow[t]{2}{*}{ Stomach } & No & 54 & 971 & 0.76 & 1.00 & 1.00 \\
\hline & Yes & 9 & 162 & 0.96 & $1.35(0.67-2.73)$ & $1.29(0.58-2.88)$ \\
\hline \multirow[t]{2}{*}{ Colon and rectum } & No & 29 & 521 & 0.41 & 1.00 & 1.00 \\
\hline & Yes & 4 & 72 & 0.42 & $1.16(0.41-3.31)$ & $1.40(0.48-4.10)$ \\
\hline \multirow[t]{2}{*}{ Liver } & No & 18 & 324 & 0.25 & 1.00 & 1.00 \\
\hline & Yes & 4 & 72 & 0.42 & $1.86(0.63-5.49)$ & $1.57(0.45-5.53)$ \\
\hline \multirow[t]{2}{*}{ Prostate } & No & 12 & 216 & 0.17 & 1.00 & 1.00 \\
\hline & Yes & 2 & 36 & 0.21 & $1.56(0.35-6.99)$ & $1.41(0.30-6.61)$ \\
\hline \multicolumn{7}{|l|}{ Women } \\
\hline \multirow[t]{2}{*}{ Lung } & No & 30 & 565 & 0.25 & 1.00 & 1.00 \\
\hline & Yes & 6 & 112 & 0.52 & $1.82(0.76-4.37)$ & $1.66(0.64-4.31)$ \\
\hline \multirow[t]{2}{*}{ Stomach } & No & 42 & 791 & 0.35 & 1.00 & 1.00 \\
\hline & Yes & 5 & 94 & 0.43 & $1.09(0.43-2.76)$ & $0.79(0.24-2.57)$ \\
\hline \multirow[t]{2}{*}{ Colon and rectum } & No & 30 & 565 & 0.25 & 1.00 & 1.00 \\
\hline & Yes & 10 & 187 & 0.86 & $3.07(1.50-6.27)$ & $3.48(1.68-7.22)$ \\
\hline \multirow[t]{2}{*}{ Liver } & No & 14 & 264 & 0.12 & 1.00 & 1.00 \\
\hline & Yes & 3 & 56 & 0.26 & $1.97(0.57-6.84)$ & $2.34(0.66-8.28)$ \\
\hline \multirow[t]{2}{*}{ Breast } & No & 3 & 57 & 0.025 & 1.00 & 1.00 \\
\hline & Yes & 3 & 56 & 0.26 & $10.70(2.11-54.36)$ & $11.90(2.25-62.84)$ \\
\hline
\end{tabular}

MetS metabolic syndrome, $\mathrm{HR}$ hazard ratio, $\mathrm{Cl}$ confidence interval

a Hazard ratios adjusted for age

b Hazard ratios adjusted for age, smoking status (never, past, or current smoker), alcohol drinking status (never, past, or current drinker), marital status (yes or no), educational attainment ( $\leq 15,16-18$, or $\geq 19$ years), physical activity (low, middle, high), occupation category (white-collar, blue-collar, or no working), and menopausal status (pre or post) only in women

number of MetS components and cancer mortality. These findings implied that subjects with MetS may need to prevention and management of cancer. Further studies are needed to confirm the influence of MetS on the risk of cancer.

\section{Additional file}

Additional file 1: Table S1. Multivariate analysis of cancer mortality with metabolic syndrome by sex, excluding participants $<40$ years. Table $\mathbf{S 2}$. Multivariate analysis of cancer mortality with the NCEP-ATP III and IDF by sex. Figure S1. The log-negative-log plot of the survival function for the number of metabolic syndrome components against time to death/ follow-up time. Figure $\mathbf{S 2}$. The log-negative-log plot of the survival function for participants with and without metabolic syndrome against time to death/follow-up time.

\section{Abbreviations}

MetS: metabolic syndrome; HR: hazard ratio; Cl: confidence interval; CVD: cardiovascular diseases; JMS: Jichi Medical School; BMI: body mass index; PAl: physical activity index; SBP: systolic blood pressure; DBP: diastolic blood pressure; TC: serum total cholesterol; HDL-C: high-density lipoprotein cholesterol; TG: triglyceride; PG: plasma glucose; ICD-10: International Classification of Diseases 10th revision; WC: waist circumference; SD: standard deviation; IQR: interquartile range; NCEP-ATP: National Cholesterol Education Program Adult Treatment Panel; JPHC: the Japan Public Health Center-based prospective study; JACC: the Japan Collaborative Cohort Study; IDF: International Diabetes Federation; IGF: insulin-like growth factor; VAT: visceral adipose tissue; FFAs: free fatty acids.

\section{Authors' contributions}

JW conducted the statistical analyses and interpretation of data. K. Kayaba, YN and SI contributed data collection and interpretation of the data. JW, EK, K. Kotani and SI conceived and designed the study, and wrote and revised the manuscript. All authors read and approved the final manuscript.

\section{Author details}

${ }^{1}$ Division of Community and Family Medicine, Center for Community Medicine, Jichi Medical University, 3311-1 Yakushiji, Shimotsuke, Tochigi 329-0498, Japan. ${ }^{2}$ Department of General Medicine, Tottori Municipal Hospital, 1-1 Matoba, Tottori, Tottori, Japan. ${ }^{3}$ Graduate School of Saitama Prefectural University, 820 Sannomiya, Koshigaya, Saitama, Japan.

\section{Acknowledgements}

We are grateful for the cooperation of all the staff involved in our study. 


\section{Competing interests}

The authors declare they have no competing interests.

\section{Availability of data and materials}

The datasets analyzed in this study are available from the corresponding author (S. Ishikawa, i-shizu@jichi.ac.jp) upon reasonable request.

\section{Consent for publication}

Not applicable.

\section{Ethics approval and consent to participate}

The present study was approved by the Institutional Review Board of Jichi Medical University, and all participants provided written informed consent at baseline.

\section{Funding}

The study was partly supported by a Grant-in-Aid from the Foundation for the Development of the Community, Tochigi, Japan, and Comprehensive Research on Cardiovascular and Life-Style Related Diseases: H26-Junkankitou [Seisaku]-Ippan-001.

\section{Publisher's Note}

Springer Nature remains neutral with regard to jurisdictional claims in published maps and institutional affiliations.

\section{Received: 19 October 2018 Accepted: 29 December 2018}

Published online: 09 January 2019

\section{References}

1. Meigs JB. Invited commentary: insulin resistance syndrome? Syndrome $X$ ? Multiple metabolic syndrome? A syndrome at all? Factor analysis reveals patterns in the fabric of correlated metabolic risk factors. Am J Epidemiol. 2000;152:908-11.

2. Russo A, Autelitano M, Bisanti L. Metabolic syndrome and cancer risk. Eur J Cancer. 2008;44:293-7.

3. Esposito K, Chiodini P, Colao A, Lenzi A, Giugliano D. Metabolic syndrome and risk of cancer: a systematic review and meta-analysis. Diabetes Care. 2012:35:2402-11.

4. Ferlay J, Soerjomataram I, Dikshit R, Eser S, Mathers C, Rebelo M, et al. Cancer incidence and mortality worldwide: sources, methods and major patterns in GLOBOCAN 2012. Int J Cancer. 2015;136:E359-86.

5. Statistics and Information Department, Minister's Secretariat, Ministry of Health, Labour and Welfare. Vital Statistics of Japan; 2016. https://www. mhlw.go.jp/english/. Accessed 19 Oct 2018.

6. Calle EE, Rodriguez C, Walker-Thurmond K, Thun MJ. Overweight, obesity, and mortality from cancer in a prospectively studied cohort of U.S. adults. N Engl J Med. 2003;348:1625-38.

7. Grossman E, Messerli FH, Boyko V, Goldbourt U. Is there an association between hypertension and cancer mortality? Am J Med. 2002;112:479-86

8. Levine W, Dyer AR, Shekelle RB, Schoenberger JA, Stamler J. Post-load plasma glucose and cancer mortality in middle-aged men and women. 12-year follow-up findings of the Chicago Heart Association Detection Project in Industry. Am J Epidemiol. 1990;131:254-62.

9. Jee SH, Ohrr H, Sull JW, Yun JE, Ji M, Samet JM. Fasting serum glucose level and cancer risk in Korean men and women. JAMA. 2005;293:194-202.

10. Hirakawa Y, Ninomiya T, Mukai N, Doi Y, Hata J, Fukuhara M, et al. Association between glucose tolerance level and cancer death in a general Japanese population: the Hisayama Study. Am J Epidemiol. 2012;176:856-64.

11. Chen Y, Wu F, Saito E, Lin Y, Song M, Luu HN, et al. Association between type 2 diabetes and risk of cancer mortality: a pooled analysis of over 771,000 individuals in the Asia Cohort Consortium. Diabetologia. 2017:60:1022-32

12. Cowan LD, O'Connell DL, Criqui MH, Barrett-Connor E, Bush TL, Wallace RB. Cancer mortality and lipid and lipoprotein levels. Lipid Research Clinics Program Mortality Follow-up Study. Am J Epidemiol. 1990;131:468-82.
13. Trevisan M, Liu J, Muti P, Misciagna G, Menotti A, Fucci F, et al. Markers of insulin resistance and colorectal cancer mortality. Cancer Epidemiol Biomarkers Prev. 2001:10:937-41.

14. Jaggers JR, Sui X, Hooker SP, LaMonte MJ, Matthews CE, Hand GA, et al. Metabolic syndrome and risk of cancer mortality in men. Eur J Cancer. 2009;45:1831-8.

15. Gathirua-Mwangi WG, Monahan PO, Murage MJ, Zhang J. Metabolic syndrome and total cancer mortality in the Third National Health and Nutrition Examination Survey. Cancer Causes Control. 2017;28:127-36.

16. Lee JS, Cho SI, Park HS. Metabolic syndrome and cancer-related mortality among Korean men and women. Ann Oncol. 2010;21:640-5.

17. Saito I, Iso H, Kokubo Y, Inoue M, Tsugane S. Metabolic syndrome and allcause and cardiovascular disease mortality: Japan Public Health Centerbased Prospective (JPHC) Study. Circ J. 2009;73:878-84.

18. Ishikawa S, Gotoh T, Nago N, Kayaba K, Jichi Medical School (JMS) Cohort Study Group. The Jichi Medical School (JMS) Cohort Study: design, baseline data and standardized mortality ratios. J Epidemiol. 2002;12:408-17.

19. Kannel WB, Sorlie P. Some health benefits of physical activity. Arch Intern Med. 1979;139:857-61.

20. Hayasaka S, Shibata Y, Ishikawa S, Kayaba K, Gotoh T, Noda T, et al. Physical activity and all-cause mortality in Japan: the Jichi Medical School (JMS) Cohort Study. J Epidemiol. 2009;19:24-7.

21. Shibata Y, Hayasaka S, Yamada T, Goto Y, Ojima T, Ishikawa S, et al. Physical activity and cardiovascular disease in Japan: the Jichi Medical School Cohort Study. 2010;20:225-30.

22. Hirokawa K, Tsutsumi A, Kayaba K, Jichi Medical School Cohort group. Occupation and plasma fibrinogen in Japanese male and female workers: the Jichi Medical School Cohort study. Soc Sci Med. 2009;68:1091-7.

23. Examination Committee of Criteria for 'Obesity Disease' in Japan, Japan Society for the Study of Obesity. New criteria for 'obesity disease' in Japan. Circ J. 2002:66:987-92.

24. Murphy TK, Calle EE, Rodriguez C, Kahn HS, Thun MJ. Body mass index and colon cancer mortality in a large prospective study. Am J Epidemiol. 2000;152:847-54.

25. Healy LA, Ryan AM, Carroll P, Ennis D, Crowley V, Boyle T, et al. Metabolic syndrome, central obesity and insulin resistance are associated with adverse pathological features in postmenopausal breast cancer. Clin Oncol (R Coll Radiol). 2010:22:281-8.

26. Hamid O, Robert C, Ribas A, Hodi S, Walpole E, Daud A, et al. Antitumou activity of pembrolizumab in advanced mucosal melanoma: a post hoc analysis of KEYNOTE-001, 002, 006. Br J Cancer. 2018. https://doi. org/10.1038/s41416-018-0207-6.

27. Shi J, Xiong L, Li J, Cao H, Jiang W, Liu B, et al. A linear dose-response relationship between fasting plasma glucose and colorectal cancer risk: Systematic review and meta-analysis. Sci Rep. 2015;5:17591.

28. Matthews CE, Sui X, LaMonte MJ, Adams AA, Hébert JR, Blair SN. Metabolic syndrome and risk of death from cancers of the digestive system. Metabolism. 2010;59:1231-9.

29. Colangelo LA, Gapstur SM, Gann PH, Dyer AR, Liu K. Colorectal cancer mortality and factors related to the insulin resistance syndrome. Cancer Epidemiol Biomarkers Prev. 2002;11:385-91.

30. Tan C, Mori M, Adachi Y, Wakai K, Suzuki S, Suzuki K, et al. Diabetes mellitus and risk of colorectal cancer mortality in Japan: the Japan Collaborative Cohort Study. Asian Pac J Cancer Prev. 2016;17:4681-8.

31. Esposito K, Chiodini P, Capuano A, Bellastella G, Maiorino MI, Rafaniello C, et al. Metabolic syndrome and postmenopausal breast cancer: systematic review and meta-analysis. Menopause. 2013;20:1301-9.

32. Expert Panel on Detection, Evaluation, and Treatment of High Blood Cholesterol in Adults. Executive summary of the third report of the National Cholesterol Education Program (NCEP) expert panel on detection, evaluation, and treatment of high blood cholesterol in adults (adult treatment panel III). JAMA. 2001;285:2486-97.

33. Guerra S, Boscari F, Avogaro A, Di Camillo B, Sparacino G, de Kreutzenberg SV. Hemodynamics assessed via approximate entropy analysis of impedance cardiography time series: effect of metabolic syndrome. Am J Physiol Heart Circ Physiol. 2011;301:H592-8.

34. Alberti KG, Zimmet P, Shaw J, IDF Epidemiology Task Force Consensus Group. The metabolic syndrome - a new worldwide definition. Lancet. 2005:366:1059-62. 
35. Committee to Evaluate Diagnostic Standards for Metabolic Syndrome Definition and the diagnostic standard for metabolic syndrome. Nihon Naika Gakkai Zasshi. 2005;94:794-809 (in Japanese).

36. Alberti KG, Eckel RH, Grundy SM, Zimmet PZ, Cleeman JI, Donato KA, et al. Harmonizing the metabolic syndrome: a joint interim statement of the International Diabetes Federation Task Force on Epidemiology and Prevention; National Heart, Lung, and Blood Institute; American Heart Association; World Heart Federation; International Atherosclerosis Society; and International Association for the Study of Obesity. Circulation. 2009;120:1640-5.

37. Polsky S, Akturk HK. Alcohol consumption, diabetes risk, and cardiovascular disease within diabetes. Curr Diab Rep. 2017;17:136.

38. Takashima N, Miura K, Hozawa A, Kadota A, Okamura T, Nakamura Y, et al. Population attributable fraction of smoking and metabolic syndrome on cardiovascular disease mortality in Japan: a 15-year follow up of NIPPON DATA90. BMC Public Health. 2010;10:306.

39. Kokubo Y, Okamura T, Yoshimasa Y, Miyamoto Y, Kawanishi K, Kotani Y, et al. Impact of metabolic syndrome components on the incidence of cardiovascular disease in a general urban Japanese population: the suita study. Hypertens Res. 2008;31:2027-35.

40. Mendonça FM, de Sousa FR, Barbosa AL, Martins SC, Araújo RL, Soares $\mathrm{R}$, et al. Metabolic syndrome and risk of cancer: which link? Metabolism. 2015;64:182-9.
41. Bastard JP, Maachi M, Lagathu C, Kim MJ, Caron M, Vidal H, et al. Recent advances in the relationship between obesity, inflammation, and insulin resistance. Eur Cytokine Netw. 2006;17:4-12.

42. Gallagher EJ, LeRoith D. Obesity and diabetes: the increased risk of cancer and cancer-related mortality. Physiol Rev. 2015;95:727-48.

43. Ben-Shmuel S, Rostoker R, Scheinman EJ, LeRoith D. Metabolic syndrome, type 2 diabetes, and cancer: epidemiology and potential mechanisms. Handb Exp Pharmacol. 2016;233:355-72.

44. Renehan AG, Frystyk J, Flyvbjerg A. Obesity and cancer risk: the role of the insulin-IGF axis. Trends Endocrinol Metab. 2006;17:328-36.

45. Fox CS, Massaro JM, Hoffmann U, Pou KM, Maurovich-Horvat P, Liu CY, et al. Abdominal visceral and subcutaneous adipose tissue compartments: association with metabolic risk factors in the Framingham Heart Study. Circulation. 2007;116:39-48.

46. Tanaka S, Togashi K, Rankinen T, Pérusse L, Leon AS, Rao DC, et al. Sex differences in the relationships of abdominal fat to cardiovascular disease risk among normal-weight white subjects. Int J Obes Relat Metab Disord. 2004;28:320-3.

47. Nielsen S, Guo Z, Johnson CM, Hensrud DD, Jensen MD. Splanchnic lipolysis in human obesity. J Clin Invest. 2004;113:1582-8.

48. Gong Y, Dou $\sqcup$, Liang J. Link between obesity and cancer: role of triglyceride/free fatty acid cycling. Eur Rev Med Pharmacol Sci. 2014; 18:2808-20.
Ready to submit your research? Choose BMC and benefit from:

- fast, convenient online submission

- thorough peer review by experienced researchers in your field

- rapid publication on acceptance

- support for research data, including large and complex data types

- gold Open Access which fosters wider collaboration and increased citations

- maximum visibility for your research: over $100 \mathrm{M}$ website views per year

At BMC, research is always in progress.

Learn more biomedcentral.com/submissions 